\title{
Analisis Mutu Biosolar pada Variasi Formulasi Blending Biodiesel dari Minyak Biji Kapuk dengan Minyak Solar
}

\section{Analysis of Biosolar in Blending Formulation of Biodiesel from Kapook Seed Oil and Solar}

\author{
Haryono $^{*}$ and Marliani \\ Departemen Kimia, Fakultas Matematika dan Ilmu Pengetahuan Alam, Universitas Padjadjaran \\ Jl. Raya Bandung-Sumedang KM. 21 Jatinangor-Sumedang 45363
}

\section{Artikel histori : \\ Diterima 10 November 2014 Diterima dalam revisi 11 Desember 2014 \\ Diterima 28 Desember 2014 Online 28 Desember 2014}

\begin{abstract}
ABSTRAK: Penelitian mengenai analisis mutu biosolar yang dihasilkan dari berbagai formulasi blending antara biodiesel dari minyak kapuk dengan minyak solar telah dilakukan. Tujuan penelitian ini adalah untuk menghasilkan formulasi blending antara biodiesel yang berasal dari minyak kapuk dengan minyak solar yang sesuai dengan standar mutu. Penelitian diawali dengan pembuatan biodiesel melalui proses degumming, reaksi esterifikasi dan transesterifikasi dengan methanol, pemurnian biodiesel, analisis mutu biodiesel, dan pembuatan biosolar pada berbagai variasi blending serta penganalisisan mutunya. Blending dilakukan pada variasi formulasi: B5, B10, B15, B20, dan B25. Hasil penelitian menunjukan bahwa formulasi blending terbaik adalah B15 $(15 \% \mathrm{v}$ biodiesel dan $85 \% \mathrm{v}$ minyak solar) ditinjau dari parameter mutu bilangan asam sebesar $0,297 \mathrm{mg} \mathrm{KOH} / \mathrm{g}$ minyak, densitas 0,845 $\mathrm{g} / \mathrm{mL}$, viskositas $2,614 \mathrm{cSt}$, dan bilangan iod $28,935 \mathrm{~g} \mathrm{I}_{2} / 100 \mathrm{~g}$.
\end{abstract}

Kata Kunci: biodiesel; biosolar; blending; formulasi; minyak kapuk.

\begin{abstract}
A research in biodiesel analysis produced from several blending formulation between biodiesel from kapook oil and solar was done. The purpose of this research was to produce blending formulation of biodiesel from kapook oil and solar to meet standard product. The research was initiated by biodiesel production, followed by degumming process, esterification and methanol transesterification, purification, analysis, and biosolar production in different variation of blending. Result indicate that best blending formulation is b15 $(15 \% \mathrm{~V}$ biodiesel and $85 \% \mathrm{~V}$ solar) that contains acid value $0.297 \mathrm{mg} \mathrm{KOH} / \mathrm{g}$ oil, density $0.845 \mathrm{~g} / \mathrm{mL}$, viscosity $2.614 \mathrm{cSt}$, and iodine value $28.935 \mathrm{I}_{2} / 100 \mathrm{~g}$.
\end{abstract}

Keywords: biodiesel; biosolar; blending method; formulation; kapook oil.

\section{Pendahuluan}

Indonesia merupakan salah satu negara penghasil minyak bumi di dunia, namun sampai saat ini masih mengimpor bahan bakar minyak (BBM) untuk mencukupi kebutuhan bahan bakar minyak di sektor transportasi dan industri. Dalam jangka panjang, impor BBM ini akan semakin mendominasi penyediaan energi nasional apabila tidak ada kebijakan pemerintahan untuk melaksanakan penganekaragaman energi dengan energi terbarukan (Risnoyatiningsih, 2010).

Salah satu jenis energi terbarukan tersebut adalah biodiesel. Sebagai bagian dari salah satu paket kebijakan ekonomi, pemerintah akan berusaha meningkatkan porsi biodiesel dalam penjualan biosolar. Pemerintah akan merevisi peraturan Menteri ESDM No.32 Tahun 2008 tentang pemanfaatan, penyediaan, dan tata niaga bahan bakar nabati, dengan tujuan untuk meningkatkan kadar campuran biodiesel di dalam biosolar sebesar 10\% dari yang sebelumnya 5\% (Gunawan, 2013).
Dalam pengembangan biodiesel, bahan baku utama yang masih dipakai adalah minyak yang berasal dari minyak kelapa sawit. Sedangkan minyak kelapa sawit termasuk sebagai minyak pangan. Oleh karena itu itu harus ada solusi tentang penyedia bahan baku biodiesel yang tidak berkompetisi dengan pangan, sehingga dapat menjaga kestabilan produksi biodiesel itu sendiri. Kapuk (Ceiba pentandra) merupakan salah satu tanaman yang berpotensi menghasilkan minyak. Minyak biji kapun ini mengandung asam lemak tidak jenuh sekitar 71,95\%, lebih tinggi dibandingkan dengan minyak kelapa (Balitro, 2007). Hal ini menyebabkan minyak biji kapuk mudah tengik, sehingga kurang baik untuk dikembangkan sebagai minyak pangan.

Pada umumnya biodiesel tidak bisa digunakan secara langsung sebagai bahan bakar pada sarana transportasi, atau bisa digunakan langsung tetapi perlu dilakukan modifikasi mesin. Penggunaan biodiesel murni (B100) berdampak negatif pada beberapa hal, seperti: korosi pada injektor dan tangki bahan bakar, pelunakan karet-karet

"Corresponding Author: +12-2345678; fax : +2345 678910

Email: authoremail@mail.com 
seal, peningkatan kebutuhan daya pemompaan, penyumbatan injektor bahan bakar, dan penyumbatan pipa/filter bahan bakar akibat pertumbuhan bakteri (Sidjabat et al., 2009). Salah satu cara untuk mengatasi permasalahan tersebut adalah melakukan blending antara biodiesel dengan minyak solar.

Blending adalah suatu proses pencampuran untuk mendapatkan produk atau umpan yang memenuhi persyaratan atau spesifikasi yang diperlukan. Untuk blending di Indonesia baru ada B5 atau yang biasa kita kenal dengan biosolar. Sampai saat ini formulasi terbaik yang dapat diterapkan dengan kondisi mesin yang sudah ada dibanyak mesin transportasi yang digunakan adalah melakukan blending dengan formulasi blending mencapai $20 \%$. istilah B20 ini merujuk atas 20\% biodiesel dan $80 \%$ solar. Begitu juga dengan B5 yang berarti 5\% biodiesel dan 95\% solar. Istilah lain seperti B10, B20 dan B25 adalah mengikuti sesuai konsentrasi biodisel yang ditambahkan. Penelitian ini bertujuan membuat biodiesel dari minyak kapuk, kemudian memcampurnya dengan minyak solar pada variasi formulasi blending B5, B10, B15, B20, dan B25.

\section{Metode Penelitian}

\subsection{Bahan Penelitian}

Bahan-bahan yang digunakan dalam penelitian ini antara lain: minyak kapuk, asam fosfat $85 \%$, asam sulfat $98 \%$, methanol teknis, kalium hidroksida, natrium hidroksida, kalium iodin, kalium iodat, etanol 95\%, air distilasi, dan natrium tiosulfat.

\subsection{Alat Penelitian}

Alat-alat yang digunakan pada penelitian ini antara lain adalah: reaktor biodiesel berupa tangki berpengaduk, tangki pencampur, hot plate magnetic stirrer, seperangkat alat distilasi, viskometer, seperangkat alat analisis dengan titrasi, seperangkat alat GC-MS, dan oven.

\subsection{Prosedur Penelitian}

Penelitian dilakukan dengan tahapan sebagai berikut: karakteristik minyak kapuk, pemurnian minyak kapuk (degumming dan pengurangan kadar air), pembuatan biodiesel melalui reaksi esterifikasi dan transesterifikasi, pemurnian biodiesel, analisis mutu biodiesel, blending biodiesel dengan minyak solar pada berbagai variasi formulasi blending, dan analisis mutu biosolar dari setiap variasi formulasi.

\subsubsection{Degumming}

Minyak kapuk sebanyak 5 liter dipanaskan pada suhu $70^{\circ} \mathrm{C}$ dan diaduk selama 15 menit, kemudian ditambahkan $0,1 \%$ asam fosfat $85 \%$ per berat minyak dan diaduk dengan kecepatan 1000 rpm selama lima menit. Campuran didiamkan selama 5 menit pada suhu kamar. Kemudian sebanyak $2 \%(\mathrm{~b} / \mathrm{b})$ air suling ditambahkan ke dalam minyak dan diaduk selama 5 menit dengan kecepatan 500 rpm. Campuran selanjutnya disentrifugasi pada kecepatan $4000 \mathrm{rpm}$ selama 15 menit, lalu disaring untuk memisahkan getah dari minyak.

\subsubsection{Esterifikasi}

Minyak biji kapuk hasil degumming dimasukkan ke dalam reaktor lalu dipanaskan sampai suhu $60^{\circ} \mathrm{C}$ ditambah asam sulfat $5 \%(\mathrm{~b} / \mathrm{b})$ dari minyak biji kapuk, kemudian ditambahkan metanol dengan perbandingan mol minyak dan metanol sebesar 1:6. Campuran direaksikan selama 120 menit. Campuran hasil reaksi dipindahkan ke dalam corong pisah untuk dipisahkan antara fase minyak dengan fase air. Fase minyak yang telah terpisah selanjutnya dicuci dengan air hangat sampai $\mathrm{pH}$ netral, lalu dilakukan distilasi untuk memisahkan metanol dan dilakukan pemisahan air dengan evaporasi.

\subsubsection{Transesterifikasi}

Fase organik hasil esterifikasi dimasukkan ke dalam reaktor kemudian ditambahkan $\mathrm{NaOH}$ sebanyak $1 \%(\mathrm{~b} / \mathrm{b})$ dari berat minyak dan metanol dengan rasio mol terhadap minyak 6:1. Reaktan dan katalis direaksikan selama 60 menit pada suhu $60^{\circ} \mathrm{C}$ ditambahkan. Setelah selesai, kemudian campuran dimasukan ke dalam corong pisah, campuran akan membentuk 2 fase, fase atas adalah metil ester (biodiesel) sedangkan fase bawah adalah gliserol. Fase atas diambil kemudian dimurnikan secara distilasi metanol, pencucian katalis $\mathrm{NaOH}$, dan penguapan air sisa.

\subsubsection{Blending}

Formulasi blending B5 dibuat dengan cara mencampurkan $5 \mathrm{~mL}$ biodiesel dengan $95 \mathrm{~mL}$ minyak solar di dalam tangki berpengaduk. Pencampuran dilakukan selama 15 menit pada suhu 55oC. Untuk formulasi blending lainnya, biosolar B10, B15, B20, dan B25 dilakukan dengan prosedur seperti pada pembuatan biosolar B5 sesuai perbandingan volume masing-masing formulasi.

\section{Hasil dan Pembahasan}

\subsection{Hasil proses degumming}

Tujuan dari proses ini untuk memisahkan gum berupa fosfatida, residu, karbohidrat, air, dan resin yang ada di dalam minyak. Minyak biji kapuk hasil degumming lebih jernih dibandingkan sebelum degumming.

Setelah dilakukan proses degumming dilakukan analisis pada minyak tersebut. Analisis yang dilakukan adalah analisis bilangan asam, densitas, dan viskositas. Hasil analisis tersebut ditampilkan pada Tabel 1 .

Tabel 1. Analisis minyak kapuk hasil degumming

\begin{tabular}{ll}
\hline \multicolumn{1}{c}{ Parameter } & Hasil \\
\hline Bilangan asam, $\mathrm{mg} \mathrm{KOH} / \mathrm{g}$ & 17,11 \\
Densitas $\left(40^{\circ} \mathrm{C}\right), \mathrm{g} / \mathrm{mL}$ & 0,907 \\
Viskositas kinematika $\left(40^{\circ} \mathrm{C}\right), \mathrm{cSt}$ & 30,09 \\
\hline
\end{tabular}




\subsection{Hasil proses esterifikasi}

Proses esterifikasi dilakukan karena nilai bilangan asam dari minyak kapuk hasil degumming masih lebih besar dari $5 \mathrm{mg} \mathrm{KOH} / \mathrm{g}$ minyak yaitu sebesar 17,11 mg KOH/g minyak (atau kadar asam lemak bebas masih sekitar 8,5\%).

Esterifikasi merupakan reaksi antara asam lemak bebas dengan alkohol yang menghasilkan air dan ester. Alkohol yang digunakan pada proses ini adalah metanol. Metanol memiliki berat molekul yang lebih ringan dibandingkan etanol (Ma \& Hanna, 1999), waktu reaksi dengan metanol lebih cepat dibandingkan etanol (Joshi et al., 2010), dan harganya yang lebih ekonomis (Zhang et al., 2003).

Katalis yang digunakan adalah asam sulfat. Reaksi esterifikasi dengan katalis asam sulfat lebih efektif dibanding jenis asam lainnya, karena menghasilkan konversi metil ester yang lebih tinggi (Choo, 2004).

Tujuan dilakukan proses estrifikasi adalah untuk menurunkan bilangan asam yang masih tinggi, hal ini dilakukan agar tidak terjadi reaksi penyabunan dalam tahap transesterifikasi yang sangat mengganggu proses pemisahan pemurnian biodiesel.

Dari hasil analisis bilangan asam, diperoleh bahwa biodiesel hasil esterifikasi memiliki bilangan asam sebesar 1,679 mg KOH/g minyak. Sedangkan sebelum esterifikasi, minyak kapuk memiliki bilangan asam 17,11 mg KOH/g minyak. Hal tersebut menunjukkan bahwa proses esterifikasi telah mampu menurunkan bilangan asam dari minyak kapuk hasil proses degumming secara sigifikan.

\subsection{Hasil proses transesterifikasi}

Proses transesterifikasi pada prinsipnya adalah merupakan proses mengeluarkan gliserin dari minyak dan mereaksikan asam lemak bebasnya dengan alkohol (biasanya metanol) menjadi metil ester menggunakan katalis basa (Hikayah \& Sudharyono, 2009). Katalis pada proses transesterifikasi adalah natrium hidroksida $(\mathrm{NaOH})$.

Dalam reaksi transesterifikasi katalis akan memecahkan rantai kimia minyak nabati sehingga rantai ester minyak nabati akan lepas, begitu ester terlepas alkohol akan segera bereaksi dengannya dan membentuk senyawa metil ester (biodiesel) dan gliserol sebagai hasil sampingnya.

Biodiesel yang dihasilkan dari proses transesterifikasi dianalisis komposisi kimianya dan beberapa parameter spesifikasi mutunya. Gambar 1 dan Tabel 2 menampilkan hasil analisis komposisi ester di dalam biodiesel yang dihasilkan dari proses trans-esterifikasi dengan GC-MS. Berdasarkan hasil analisis tersebut, jenis metil ester yang dominan di dalam biodiesel adalah metil linoleat sebesar $38,43 \%$, diikuti metil oleat sebesar 24,84\%. Hasil analisis tersebut sesuai dengan komposisi asam lemak di dalam minyak kapuk yang didominasi oleh asam lemak tidak jenuh sekitar 71,95\% (Balitro, 2007).

\subsection{Hasil analisis biodiesel}

Tabel 3.2 dan Tabel 3.3 menampilkan hasil analisis beberapa parameter spesifikasi mutu biodiesel yang kemudian dibandingkan dengan standar biodiesel (SNI 047182-2006).
Tabel 2. Kandungan biodiesel minyak kapuk berdasarkan hasil analisis dengan GC-MS

\begin{tabular}{llll}
\hline $\begin{array}{l}\text { No } \\
\text { Puncak }\end{array}$ & $\begin{array}{l}\text { Waktu } \\
\text { Retensi } \\
\text { (menit) }\end{array}$ & $\begin{array}{l}\text { Nisbah } \\
\text { Area } \\
(\%)\end{array}$ & $\begin{array}{l}\text { Dugaan } \\
\text { Senyawa }\end{array}$ \\
\hline 1 & 17,392 & 24,78 & Metil palmitat \\
3 & 20,542 & 38,43 & Metil linoleat \\
4 & 20,676 & 24,84 & Metil oleat \\
6 & 21,207 & 3,72 & Metil stearat \\
9 & 25,63 & 0,41 & Metil arachidat \\
\hline
\end{tabular}

Tabel 3. Hasil analisis biodiesel dari proses transesterifikasi (katalis $\mathrm{NaOH}, 1$ jam, suhu $\left.60^{\circ} \mathrm{C}\right)$

\begin{tabular}{lccc}
\hline \multicolumn{1}{c}{ Parameter } & Satuan & Hasil & $\begin{array}{c}\text { Standar } \\
\text { Biodiesel }^{1)}\end{array}$ \\
\hline Bilangan asam & $\begin{array}{c}\text { mg KOH/g } \\
\text { minyak } \\
\text { Densitas }\end{array}$ & 0,778 & Max 0,8 \\
Viskositas & $\mathrm{g} / \mathrm{mL}$ & 0,876 & $0,85-0,89$ \\
Bilangan & $\mathrm{cSt}$ & 3,213 & $2,3-6,0$ \\
$\quad$ penyabunan & $\begin{array}{c}\mathrm{mg} \mathrm{KOH} / \mathrm{g} \\
\text { minyak }\end{array}$ & 110,629 & - \\
$\begin{array}{l}\text { Bilangan iod } \\
\text { Bilangan setana }\end{array}$ & massa & 39,889 & Max 115 \\
\hline 1) SNI 04-7182-2006 & 86,89 & Min 51 \\
\hline
\end{tabular}

Parameter spesifikasi mutu yang ditentukan adalah bilangan asam, bilangan penyabunan, densitas, viskositas, bilangan iod serta bilangan cetana. Untuk bilangan cetana (CN) ditentukan dengan pendekatan sebagai fungsi bilangan penyabunan (SN) dan bilangan iodine (IV) dalam bentuk persamaan (Azam et al., 2005) persamaan 1.

$\mathrm{CN}=46,3+5458 / \mathrm{SN}-0,255 \times \mathrm{IV}$ (1)

Berdasarkan hasil analisis, biodiesel yang dihasilkan dari minyak kapuk pada penelitian ini telah sesuai dengan standar mutu menurut SNI.

\subsection{Hasil proses formulasi blending}

Formulasi blending dilakukan dengan variasi formulasi B5, B10, B15, B20, dan B25. Proses blending dilakukan di dalam tangki pencampur pada suhu 55oC selama 15 menit. Penampilan fisik hasil dari semua formulasi blending ditampilkan pada Gambar 1.

Semua biosolar dari proses blending selanjutnya dilakukan analisis parameter spesifikasi mutunya yang meliputi: bilangan asam, densitas, viskositas, bilangan penyabunan, dan bilangan iodin. 


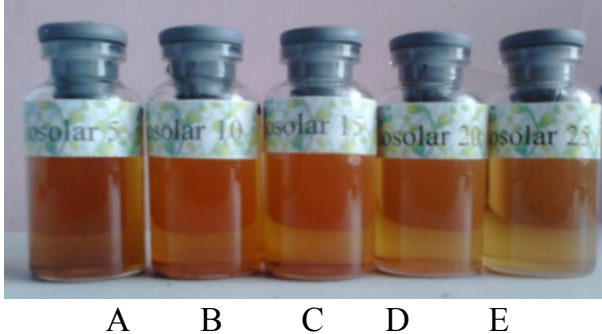

Gambar 1. Biosolar: B5 (A), B10 (B), B15 (C), B20 (D), dan B25 (E).

\subsubsection{Perbandingan bilangan asam biosolar pada berbagai formulasi blending}

Bilangan asam

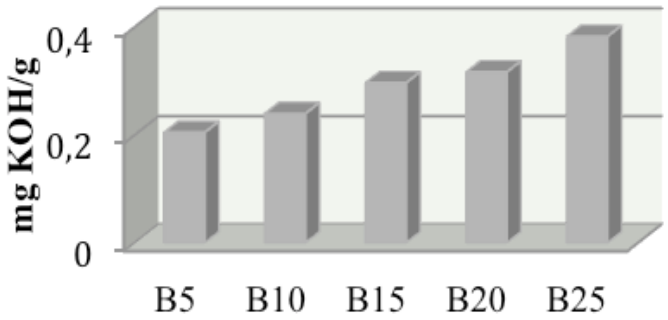

Gambar 2. Perbandingan bilangan asam biosolar pada berbagai formulasi blending

Sesuai hasil analisis bilangan asam pada Gambar 2 tersebut, nampak bahwa penggunaan biodiesel yang semakin banyak pada formulasi blending dengan minyak solar akan berdampak pada semakin naiknya bilangan asam. Hal ini menunjukkan bahwa nilai bilangan asam pada biosolar dikontribusi oleh keberadaan biodiesel. Semakin banyak biodiesel yang ditambahkan maka akan meningkatkan kadar asam lemak bebas yang masing terkandung di dalam biodiesel.

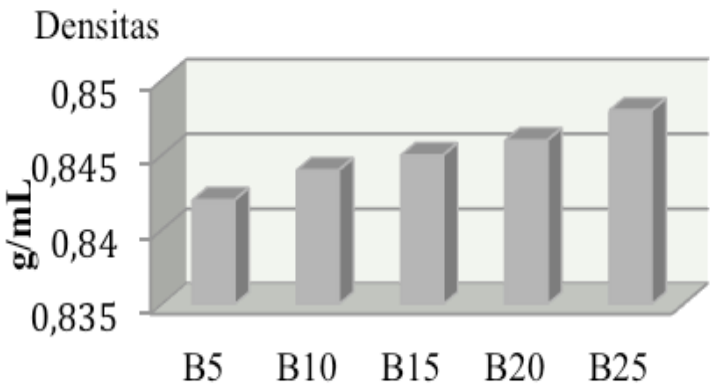

Gambar 3. Perbandingan densitas biosolar pada berbagai formulasi blending

\subsubsection{Perbandingan densitas biosolar pada berbagai formulasi blending}

Nilai densitas biodiesel lebih besar dibandingkan densitas minyak solar (Gerpen et al., 2004). Hal tersebut berdampak pada kenaikan densitas dari biosolar jika formulasi blending dilakukan dengan memperbanyak komposisi biodiesel. Hasil analisis densitas biosolar dari berbagai formulasi blending ditampilkan pada Gambar 3.

\subsubsection{Perbandingan viskositas biosolar pada berbagai formulasi blending}

Penambahan biodiesel dalam formulasi blending yang semakin meningkat berdampak pada semakin naiknya viskositas dari biosolar yang dihasilkan (Gambar 4). Hal ini disebabkan minyak solar memiliki viskositas yang lebih rendah daripada biodiesel. Apabila keduanya dicampurkan, maka campuran dari biodiesel dan minyak solar ini akan mempunyai viskositas lebih encer dari biodiesel tapi tidak lebih encer dari minyak solar. Sehingga dengan jumlah biodiesel yang semakin bertambah pada formulasi biosolar, hal terebut akan meningkatkan viskositas biosolar hasil blending.

Viskositas ini berkaitan dengan komposisi asam lemak bahan baku, jumlah ikatan rangkap, dan kemurnian produk akhir. Viskositas kinematik berbanding lurus dengan panjang rantai karbon. Semakin panjang rantai karbon asam lemak dan alkohol maka viskositas akan semakin tinggi. Sebaliknya viskositas semakin tinggi jika minyak semakin jenuh (Mittelbach \& Remschmidt, 2006).

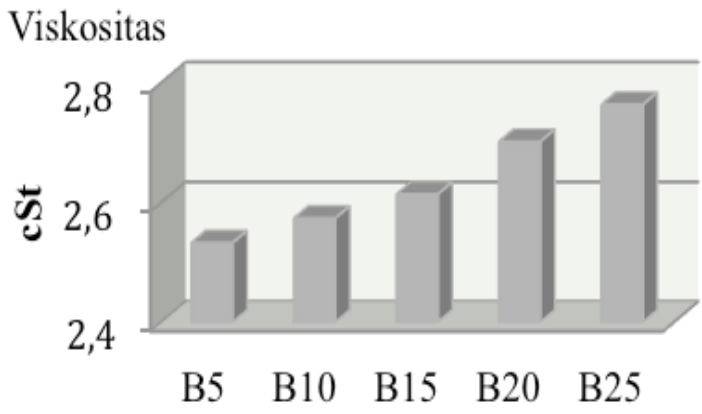

Gambar 4. Perbandingan viskositas biosolar pada berbagai formulasi blending

\subsubsection{Perbandingan bilangan penyabunan biosolar} pada berbagai formulasi blending

Gambar 5 menunjukkan bahwa bilangan penyabunan biosolar yang dihasilkan dari formulasi blending dengan komposisi biodiesel lebih banyak, memiliki bilangan penyabunan yang semakin rendah.

Peristiwa tersebut terjadi dikarenakan bilangan penyabunan pada biosolar merupakan kontribusi dari biodiesel. Sehingga dengan penggunaan biodiesel pada formulasi blending yang semakin banyak akan berdampak pada semakin besarnya berat molekul rata-rata dari biosolar yang dihasilkan. Sedang secara umum, terdapat kecenderungan bahwa dengan semakin besarnya berat molekul suatu senyawa organik yang sejenis, bilangan penyabunannya akan semakin turun (Mittelbach \& Remschmidt, 2006). 


\section{Bilangan penyabunan}



Gambar 5. Perbandingan bilangan penyabunan pada berbagai formulasi blending

\subsubsection{Perbandingan bilangan iod pada berbagai formulasi blending}

Bilangan iod merupakan ukuran empirik banyaknya ikatan rangkap dua di dalam asam-asam lemak penyusun biodiesel. Satu mol iodium yang teradisi setara dengan satu mol ikatan rangkap dua pada biodiesel. Sedangkan minyak solar sendiri berupa senyawa hidrokarbon jenuh, sehingga pada formulasi blending dengan penggunaan biodiesel yang semakin banyak akan mengakibatkan bilangan iod dari biosolar yang dihasilkan semakin besar. Hal tersebut seperti yang ditunjukkan pada Gambar 6 .

\section{Bilangan iodin}

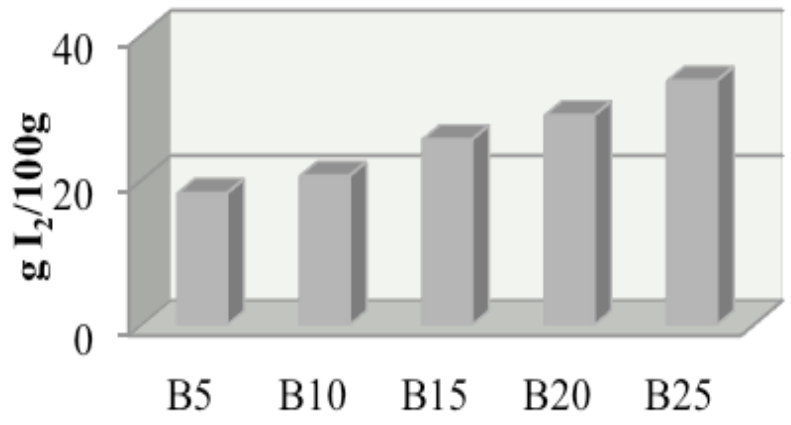

Gambar 6. Perbandingan bilangan iod pada berbagai formulasi blendin

\subsubsection{Perbandingan spesifikasi mutu biosolar B5, B15, dan B20}

Hasil formulasi blending antara biodiesel dari minyak kapuk dan minyak solar dari penelitian ini dibandingkan dalam hal spesifikasi mutunya dengan standar mutu biosolar menurut ASTM D 4052.

Pada perbandingan spesifikasi mutu ini, dikarenakan keterbatasan parameter yang dibandingkan dan sumber informasi formulasi blending, maka formulasi blending yang dapat dibandingkan hanya B5 dan B20. Sedangkan spesifikasi mutu biosolar B15 dari penelitian ini dimanfaatkan sebatas sebagai intepretasi dan proyeksi mutu biosolar. Parameter mutu yang diperbandingkan adalah densitas, viskositas (pada suhu $40^{\circ} \mathrm{C}$ ), dan bilangan asam. Perbandingan nilai parameter mutu tersebut ditampilkan pada Tabel 4 .
Tabel 4. Perbandingan nilai parameter mutu biosolar B5, B15, dan B20

\begin{tabular}{lccccc}
\hline \multirow{2}{*}{$\begin{array}{l}\text { Spesifikasi } \\
\text { Mutu }\end{array}$} & \multicolumn{2}{c}{$\begin{array}{c}\text { ASTM } \\
\text { D 4052* }\end{array}$} & \multicolumn{3}{c}{ Penelitian ini } \\
\cline { 2 - 6 } & B5 & B20 & B5 & B15 & B20 \\
\hline $\begin{array}{l}\text { Densitas, } \\
\text { g/mL }\end{array}$ & 0,839 & 0,846 & 0,842 & 0,845 & 0,846 \\
$\begin{array}{l}\text { Viskositas } \\
\left(40^{\circ} \mathrm{C}\right), \mathrm{cSt}\end{array}$ & 3,223 & 3,271 & 2,533 & 2,614 & 2,702 \\
$\begin{array}{l}\text { Bilangan } \\
\text { asam, } \\
\text { mg KOH/g }\end{array}$ & \multicolumn{2}{c}{$\begin{array}{l}\text { Maks. 0,30 } \\
\text { (B6- B20) }\end{array}$} & 0,205 & 0,297 & 0,317 \\
\hline *anduglia, 2009 & & & & \\
\hline
\end{tabular}

\section{Kesimpulan}

1. Minyak biji kapuk berpotensi sebagai bahan baku pembuatan biodiesel

2. Biodiesel yang dihasilkan dari penelitian sudah memenuhi standar SNI 04-7182-2006 dilihat dari segi bilangan asam sebesar $0,7775 \mathrm{mg} \mathrm{KOH} / \mathrm{g}$ minyak, densitas 0,8756 g/mL, viskositas 3,2127 cSt, bilangan penyabunan $110,6292 \mathrm{mg} \mathrm{KOH} / \mathrm{g}$ minyak, bilangan iod 40,51 g I2/100g dan bilangan setana 85,305.

3. Formulasi terbaik dari hasil penelitian adalah B15, yaitu bilangan asam 0,297 $\mathrm{mg} \mathrm{KOH} / \mathrm{g}$ minyak, densitas $0,845 \mathrm{~g} / \mathrm{mL}$, viskositas 2,614 cSt, bilangan penyabunan 74,96 $\mathrm{mg} \mathrm{KOH} / \mathrm{g}$ minyak, dan bilangan iod $28,935 \mathrm{~g} \mathrm{I} 2 / 100 \mathrm{~g}$.

\section{Daftar Pustaka}

Azam, M.M., Waris, A., \& Nahar, N.M., 2005, Prospects and potential of fatty acid methyl esters of some nontraditional seed oils for use as biodiesel in India, $J$. Biomass \& Bioenergy., Vol.29, July: 293-302.

Balitro, 2007, Biji kapuk: sumber bahan baku minyak diesel nabati, www.pustaka.litbang.deptan.go. $\mathrm{id} /$ publikasi/wr24202j.pdf (diakses Juli 2014).

Choo, Y.M., 2004, Transesterification of palm oil: effect of reaction parameters, J. Oil Palm Resource, Vol.16 No.2:1-11.

Ganduglia, F., 2009, Handbook of Biofuels, IICA and ARPEL, San Jose, Costa Rica.

Gerpen, V.J., Shanks, B., Pruszko, R., Clements, D., \& Knothe, G., 2004, Biodiesel analytical methodsNational Renewable Energy Laboratory, http://www.nrel.gov (diakses Juli 2004).

Gunawan, H., 2013, Mandatori biodiesel bisa ditambah 20 persen, www. Tribunnews.com/bisnis (diakses 29 Agustus 2013).

Joshi, H., Moser, B.R., Toler, J., \& Walker, T., 2010, Preparation and fuel properties of mixtures of soybean oil methyl and ethyl esters. J. Biomass and Bioenergy, Vol.34: 14-20.

Ma, F., Hanna, M.A. 1999. Biodiesel production: a review, J. Bioresources Technology, Vol.70: 1-15.

Mittelbach, M. \& Remschmidt, C., 2006, Biodiesel: the Comprehensive Handbook, third edition: Boersedruck Ges, Austria. 
Hikayat, R., Sundaryono, A., 2009. Perengkahan Katalitik Metil Ester dari Limbah Cair Pengolahan CPO menjadi Biofuel dengan katalis zeolit serta implementasinya pada pembelajran kimia, SMA FKIP Kimia Universitas Bengkulu (tidak dipublikasikan).

Risnoyatiningsih, S., 2010, Biodiesel from avocado seeds by transesterification process, Jurnal Teknik Kimia Vol.5(1): 345-351.

Sidjabat, O., Haris, A., \& Purnomo, H. (Lemigas: Process Technology Division), 2009, The effect of biodiesel blending by splash technique in engine performance, The 7th Asian Petroleum Technology Symposium, Ho Chi Minh, 18-19 February 2009.

Zhang, Y., Dube, M.A., McLean, D.D., \& Kates, M., 2003, Biodiesel production from waste cooking oil: process design and technological assessment. J. Bioresource Technology, Vol.89:1-16. 